Pacific Journal of Mathematics

SEQUENCES OF BOUNDED SUMMABILITY DOMAINS 


\title{
SEQUENCES OF BOUNDED SUMMABILITY DOMAINS
}

\author{
R. M. DeVos and F. W. Hartmann
}

\begin{abstract}
C. Goffman and G. N. Wollan conjectured that the bounded summability field of a regular matrix $A$ is so thin that the union of countably many such sets is not dense in $m$. G. M. Petersen proved this conjecture. This result is strengthened by showing if $A$ is a noncoercive matrix whose summability field contains all the finite sequences then its bounded summability field is so thin that the union of countably many such sets is not dense in $m$. An example is given to show that the condition of containing the finite sequences is necessary.
\end{abstract}

Preliminaries. Let $m$ and $c$ be respectively the Banach spaces of bounded and convergent sequences, $x=\left\{x_{n}\right\}$, of complex numbers with norm $\|x\|_{\infty}=\sup _{n}\left|x_{n}\right|, B(x, r)=\left\{z \in m:\|x+z\|_{\infty}<r\right\}$. Denote the $n$th section of $x$ by $P_{n}(x)=\left(x_{1}, \cdots, x_{n}, 0,0, \cdots\right)$. For each infinite matrix $A$ the set of $x$ transformed by $A$ to convergent sequences is called the summability field of $A$ and denoted by $c_{A}$. The set of bounded sequences in $c_{A}$ is called the bounded summability field of $A$ and is denoted by $\mathscr{A}$. $A$ is called conservative if and only if $c_{A} \supset c$, regular if and only if $A$ is conservative and limits are preserved, coercive if and only if $c_{A} \supset m$. If $A=\left(a_{n k}\right)$, then the $A$ transform of $x$ is designated by $A x=\left\{(A x)_{n}\right\}=\left\{\sum_{k} a_{n k} x_{k}\right\} . \quad A$ is conservative if and only if $\|A\|_{\infty}=\sup _{n} \sum_{k}\left|a_{n k}\right|<\infty, a_{k}=\lim _{n} a_{n k}$ exists for each $k$ and $\lim _{n} \sum_{k} a_{n k}$ exists [5, p. 165]. A is coercive if and only if $\sum_{k}\left|a_{n k}\right|$ converges uniformly in $n$ and $a_{k}$ exists for each $k\left[5\right.$, p. 169]. Define the essential norm of $A$ by $\|A\|_{c}=$ $\lim \sup _{n} \sum_{k}\left|a_{n k}-a_{k}\right|$ whenever $a_{k}$ exists for each $k$. (Note \|\|$_{c}$ is not a true norm, since \|\|$_{c}$ may be infinite.)

Let $E^{\infty}$ be the set of all finite sequences and $N_{0}$ the set of all sequences of 0 's and 1's. Using binary expansions there is a natural injective mapping of $(0,1)$ onto all but a countable subset of $N_{0}$.

MaIn Results. C. Goffman and G. N. Wollan conjectured [4] that the bounded summability field of regular $A$ is so thin that the union of countably many such sets is not dense in $m$. G. M. Petersen proved this conjecture [6]. We strengthen that result and show that in a certain sense our result is best possible.

THEOREM. Let $\left\{A_{i}\right\}$ be a countable collection of noncoercive matrices with $\mathscr{A}_{i} \supset E^{\infty}, i=1,2, \cdots$, then $\bigcup_{i=1}^{\infty} \mathscr{A}_{i}$ is not dense in $m$.

We prove the theorem through a series of lemmas. Since we 
want $E^{\infty} \subset \mathscr{A}$, we shall assume all $A$ in the sequel have convergent columns.

Lemma 1. Let $\|A\|_{\infty}<\infty$ then $\|A\|_{c}=0$ if and only if $A$ is coercive.

Proof. Suppose $A$ is coercive. Let $\varepsilon>0$. There exists $k_{0}$

$$
\sum_{k=k_{0}+1}^{\infty}\left|a_{n k}\right|<\varepsilon / 3
$$

for all $n$. Since $\left\{a_{k}\right\} \in \ell^{1}$, there is a $k_{1}$ such that $k>k_{1}$ implies

$$
\sum_{k=k_{1}+1}^{\infty}\left|\alpha_{k}\right|<\varepsilon / 3 \text {. }
$$

Let $k_{2}=\max \left(k_{1}, k_{0}\right)$. There exists $n_{0}=n_{0}\left(k_{2}\right)$ such that $n>n_{0}$ implies

$$
\sum_{n=1}^{k_{2}}\left|a_{n k}-a_{k}\right|<\varepsilon / 3 \text {. }
$$

Let $n>n_{0}$ then

$$
\begin{aligned}
\sum_{k=1}^{\infty}\left|a_{n k}-a_{k}\right| & =\sum_{k=1}^{k_{2}}\left|a_{n k}-a_{k}\right|+\sum_{k=\kappa_{2}+1}^{\infty}\left|a_{n k}-a_{k}\right| \\
& \leqq \sum_{k=1}^{k_{2}}\left|a_{n k}-a_{k}\right|+\sum_{k=k_{2}+1}^{\infty}\left|a_{n k}\right|+\sum_{k=k_{2}+1}^{\infty}\left|a_{k}\right| \\
& <\varepsilon / 3+\varepsilon / 3+\varepsilon / 3=\varepsilon .
\end{aligned}
$$

Conversely assume $A$ is noncoercive. There exists $\varepsilon>0$ and an increasing sequence of positive integers $\{n(p)\}_{p=1}^{\infty}$ such that $\sum_{k=p+1}^{\infty}\left|a_{n(p), k}\right|>\varepsilon$. There exists $k_{0}$ such that $\sum_{k=k_{0}+1}^{\infty}\left|a_{k}\right|<\varepsilon / 2$. Pick $p$ with $p>k_{0}$ then

$$
\begin{aligned}
\sum_{k=1}^{\infty}\left|a_{n(p), k}-a_{k}\right| & \geqq \sum_{k=k_{0}+1}^{\infty}\left|a_{n(p), k}-a_{k}\right| \\
& \geqq \sum_{k=k_{0}+1}^{\infty}\left|a_{n(p), k}\right|-\sum_{k=k_{0}+1}^{\infty}\left|\alpha_{k}\right| \\
& \geqq \varepsilon-\varepsilon / 2=\varepsilon / 2 .
\end{aligned}
$$

Therefore $\|A\|_{c}>0$.

Let $\Gamma(c, c)$ be the Banach algebra of conservative matrices and $\mathscr{K}$ be the ideal of compact operators. It is well known [8] that $A \in \mathscr{K}$ if and only if $A$ is coercive. $\Gamma(c, c) / \mathscr{K}$ is a Banach algebra and is called a Calkin algebra [2]. It is easily seen that \|\|$_{c}$ is the norm in the Calkin algebra.

Lemma 2. Let $\|A\|_{c}<\infty$ and $a$ and $b$ be cluster points of $A x$, 
$x \in m$, then $|a-b| \leqq 2\|A\|_{c}\|x\|_{\infty}$.

Proof. Let $a$ and $b$ be cluster points of $A x$ and $\varepsilon>0$. There exist increasing sequences of positive integers $\{n(i)\},\{m(j)\}$ and $N_{0}$ such that for $n(i), m(j)>N_{\text {r }}$

$$
\left|\sum_{k} a_{n(i), k} x_{k}-a\right|<\varepsilon
$$

and

$$
\left|\sum_{k} a_{m(j), k} x_{k}-b\right|<\varepsilon .
$$

There exists $N_{1}$ such that $n>N_{1}$ implies

$$
\sum_{k}\left|a_{n k}-a_{k}\right|<\|A\|_{c}+\varepsilon .
$$

Let $n(i), m(j)>\max \left(N_{0}, N_{1}\right)$ then

$$
\begin{aligned}
|a-b| & \leqq\left|\sum_{k} a_{n(i), k} x_{k}-\sum_{k} a_{m(j), k} x_{k}\right|+2 \varepsilon \\
& \leqq \sum_{k}\left|a_{n(i), k}-a_{m(j), k}\right|\left|x_{k}\right|+2 \varepsilon \\
& \leqq\|x\|_{\infty} \sum_{k}\left|\left(a_{n(i), k}-a_{k}\right)-\left(a_{m(j), k}-a_{k}\right)\right|+2 \varepsilon \\
& \leqq\|x\|_{\infty}\left(\|A\|_{c}+\varepsilon+\|A\|_{c}+\varepsilon\right)+2 \varepsilon .
\end{aligned}
$$

Since $\varepsilon$ is arbitrary the conclusion follows.

The next lemma is due to Bennett and Kalton and appears as Lemma 7 of $[1$, p. 577].

Lemma 3. (Bennett and Kalton). If $z_{1}, z_{2}, \cdots, z_{n}$ is any finite collection of complex numbers then there exists a subset $J(n)$ of $\{1, \cdots, n\}$ such that

$$
\left|\sum_{j \in J(n)} z_{j}\right| \geqq \frac{1}{4} \sum_{i=1}^{n}\left|z_{i}\right|
$$

LEMma 4. If $\|A\|=\infty$, then there exists $E(A)$ with $E(A) \subset N_{0}$, $N_{0} \backslash E(A)$ of first category and if $u \in E(A)$ then $B(u, 1 / 32) \cap \mathscr{A}=\varnothing$.

Proof. Case 1. Assume all the rows of $A$ are in $\ell^{1}$. Let $\|A\|=\infty$. Pick sequences $n(k)$ and $q(k)$ inductively such that $n(1)=1$ and

(i) $\sum_{i=q(k)+1}^{\infty}\left|a_{n(k), i}\right|<2^{-k}$

(ii) $\sum_{i=q(k-1)+1}^{q(k)}\left|a_{n(k), i}\right|>(65 / 7) \sup _{j}\left\{\sum_{i=1}^{q(k-1)}\left|a_{j i}\right|\right\}$.

By Lemma 3 select $J(k) \subset\{q(k-1)+1, \cdots, q(k)\}$ with 


$$
\left|\sum_{i \in J(k)} a_{n(k), i}\right| \geqq \frac{1}{4} \sum_{i=q(k-1)+1}^{q(k)}\left|a_{n(k), i}\right| .
$$

For each natural number $k$ define the sequence $u^{k}$ by $u_{i}^{\kappa}=1$ if $i \epsilon$ $J(k), u_{i}^{k}=0$ if $i \notin J(k)$. Let

$$
O_{k}=\left\{u \in N_{0}:\left(P_{q(k)}-P_{q(k-1)}\right)\left(u-u^{k}\right)=0\right\} \text {. }
$$

If $E(A)=\bigcap_{n=1}^{\infty} \bigcup_{k=n}^{\infty} O_{k}$, then $E(A)$ is of second category. [ $\bigcup_{k=n}^{\infty} O_{k}$ is open and dense, hence by the Baire theorem $E(A)$ is of second category.] Let $u \in E(A)$ and $\|z\|_{\infty}<1 / 32$. $u$ is in an infinite number of the $O_{k}$. Let $u \in O_{r}$. Then

$$
\begin{aligned}
\mid(A(u & +z))_{n(r)}|\geqq|(A u)_{n(r)}|-|(A z)_{n(r)} \mid \\
\geqq & \left|\sum_{i=q(r-1)+1}^{q(r)} a_{n(r), i} u_{i}\right|-\left|\sum_{i=1}^{q(r-1)} a_{n(r), i} u_{i}\right|-\left|\sum_{i=q(r)+1}^{\infty} a_{n(r), i} u_{i}\right| \\
& -\frac{1}{32} \sum_{i=1}^{\infty}\left|a_{n(r), i}\right| \\
\geqq & \frac{1}{4} \sum_{i=q(r-1)+1}^{q(r)}\left|a_{n(r), i}\right|-\frac{33}{32} \sum_{i=1}^{q(r-1)}\left|a_{n(r), i}\right| \\
& -\frac{33}{32} \sum_{i=q(r)+1}^{\infty}\left|a_{n(r), i}\right|-\frac{1}{32} \sum_{i=q(r-1)+1}^{q(r)}\left|a_{n(r), i}\right| \\
\geqq & \frac{7}{32} \sum_{i=q(r-1)+1}^{q(r)}\left|a_{n(r), i}\right|-\frac{33}{32} \sum_{i=1}^{q(r-1)}\left|\alpha_{n(r), i}\right|-\frac{33}{32} 2^{-r} \\
\geqq & \frac{7}{32} \frac{65}{7} \sup _{j}\left\{\sum_{i=1}^{q(r-1)}\left|a_{j i}\right|\right\}-\frac{33}{32} \sup _{j}\left\{\sum_{i=1}^{q(r-1)}\left|a_{j i}\right|\right\}-2^{1-r} \\
\geqq & \sup _{j}\left\{\sum_{i=1}^{q(r-1)}\left|a_{j i}\right|\right\}-2^{1-r} \longrightarrow \infty \text { as } \longrightarrow \underset{1}{\longrightarrow} .
\end{aligned}
$$

Hence the $A$ transform of $u+z$ is unbounded.

Case 2. Let $A$ have one row, $x$, not in $\ell^{1}$. Let $B=\left(b_{n k}\right)$ where $b_{n k}=P_{n}(x), n=1,2, \cdots$ Then $\mathscr{A} \subset \mathscr{B}$ and $B$ satisfies the hypothesis of Case 1. Let $E(A)=E(B)$ then $E(A) \cap \mathscr{A}=\varnothing$ and $E(A)$ satisfies the other conditions of the lemma's conclusion.

LEMMA 5. If $\|A\|<\infty$, and $A$ is noncoercive then there is $E(A)$ with $E(A) \subseteq N_{0}, N_{0} \backslash E(A)$ is of first category and if $u \in E(A)$, then $B(u, 1 / 32) \cap \mathscr{L}=\varnothing$.

Proof. Case 1. Assume $\alpha_{k}=0, k=1,2, \cdots$ Let $\alpha^{n}$ be the $n$th row of $A$. Using an argument similar to that of Petersen and Baker [6] (see also the construction of Lemma 4) it can be shown that without lose of generality one may assume that the rows and columns of $A$ are in $E^{\infty}$ and moving to the right, (if $P_{j} \alpha^{n}=0$ then 
$P_{j} \alpha^{m}=0$ for $\left.m \geqq n\right)$. By Lemma $1\|A\|_{c}>0$. Hence there exists increasing sequences $n(j)$ and $r(j)$ of positive integers such that

(i) $\sum_{k=r(j-1)+1}^{r(j)}\left|a_{n(j), k}\right|>\|A\|_{c} / 2$

(ii) $\left(P_{r^{(j)}}-P_{r(j-1)}\right) \alpha^{n(j)}=\alpha^{n(j)}$.

Let $J(2 j)$ be a subset of $r(2 j-1)$ to $r(2 j)-1$ with

$$
\left|\sum_{k \in J(2 j)} a_{n(j), k}\right| \geqq \frac{1}{4} \sum_{j=r(2 j-1)+1}^{r(2 j)}\left|a_{n(j), k}\right| \geqq \frac{\|A\|_{c}}{8}
$$

(see Lemma 3). Define $O_{j}=\left\{u \in N_{0}: u_{k}=1\right.$ if $k \in J(2 j), u_{k}=0$ if $r(2 j-2)+1 \leqq k \leqq r(2 j), k \notin J(2 j)\}$. Since only a finite number of coordinates are specified for elements of $O_{j}, O_{j}$ is open. For each $k, \bigcup_{j=k}^{\infty} O_{j}$ is open and dense, hence by the Baire category theorem. $\bigcap_{k=1}^{\infty} \bigcup_{j=k}^{\infty} O_{j}$ is of second category. Let $E(A)=\left\{u \in N_{0}: A u\right.$ has cluster points, $a, b$, with $\left.|a-b| \geqq\|A\|_{o} / 8\right\}$. By construction each element of $\bigcap_{k=1}^{\infty} \bigcup_{j=k}^{\infty} O_{j}$ has 0 and $a\left(|a|>\|A\|_{c} / 8\right)$ as cluster points thus $E(A)$ is of second category. Let $u \in E(A)$ and $\|z\|_{\infty}<1 / 32$ and consider $A(u+z)$. $A u$ has two cluster points separated in distance by at least $\|A\|_{0} / 8$, and $A(z)$ has cluster points separated by at most 2(1/32) $\|A\|_{c}$ (Lemma 2). Therefore $A(u+z)$ has at least two cluster points; hence $u+z \notin \mathscr{A}$.

Case 2. Let $a_{k} \neq 0$ for some $k$. Define $B=\left(b_{n k}\right)$ where $b_{n k}=$ $a_{k}, n, k=1,2, \cdots . B$ transforms every bounded sequence to a constant sequence, thus the cluster points of $(A-B) u, u \in m$, are a shift of those of $A u$, and $A-B$ satisfies the hypothesis of Case 1. Thus the conclusion follows in a manner similar to Case 1.

Proof of Theorem. Let $A_{i}$ be a countable collection of noncoercive matrices with $\mathscr{A}_{i} \supset E^{\infty}, i=1,2, \ldots$. By Lemmas 4 and 5 for each $i$ there exists $E\left(A_{i}\right) \subseteq N_{0}, E\left(A_{i}\right)$ of second category, and if $u \in E\left(A_{i}\right), B(u, 1 / 32) \cap \mathscr{A}_{i}=\varnothing$. Thus $\bigcap_{i=1}^{\infty} E\left(A_{i}\right) \neq \varnothing$ and if $u \epsilon$ $\bigcap_{i=1}^{\infty} E\left(A_{i}\right)$, then $B(u, 1 / 32) \cap\left(\bigcup_{i=1}^{\infty} \mathscr{A}_{i}\right)=\varnothing$. Hence $\bigcup_{i=1}^{\infty} \mathscr{A}_{i}$ is not dense in $m$.

Goffman and Wollan in [4] gave an example of a countable family of $F K$ spaces contained in $m$ whose union is dense in $m$. They can be realized as summability domains in the following manner. Let $\left\{r_{i}\right\}$ be a denumeration of the nonzero rationals. Define $A_{i}=$ $\left(a_{n k}^{(i)}\right)$ by

$$
\begin{array}{ll}
\text { (i) } & a_{n 1}^{(i)}=r_{i}, a_{n 2}^{(i)}=-1, n=1,3,5, \cdots \\
\text { (ii) } & a_{n 1}^{(i)}=-1, a_{n 2}^{(i)}=r_{i}^{-1}, n=2,4,6, \cdots \\
& a_{n k}=0, k \geqq 3, n=1,2,3, \cdots
\end{array}
$$

Then $\mathscr{A}_{i}=\left\{\left(x_{n}\right)_{n=1}^{\infty}: x_{1}=x, x_{2}=r_{i} x, x_{k}\right.$ arbitrary for $k \geqq 3$ and $x$ complex $\} \cap m$. Each $\mathscr{A}_{i}$ is nowhere dense in $m$, but $\bigcup_{i=1}^{\infty} \mathscr{A}_{i}$ is dense. Note, however, that $\mathscr{A}_{i} \not \supset E^{\infty}$. Hence the hypothesis that each 
$\mathscr{A}_{i} \supseteq E^{\infty}$ cannot be removed and our result is in some sense best possible.

Although we have proved our result only for $\mathscr{A}_{i}$, we conjecture that the following more general result holds:

Conjecture. If $\left\{F_{i}\right\}$ is a countable collection of $F K$-spaces each containing $E^{\infty}$ but not $m$, then $\bigcup_{i=1}^{\infty} F_{i}$ is not dense in $m$. (See [8] for definitions and basic results.)

\section{REFERENCES}

1. G. Bennett and N. J. Kalton, FK-spaces containing $c_{0}$, Duke Math. J., 39 (1972), 561-582.

2. S. R. Caradus, W. E. Pfaffenberger and Bertram Yood, Calkin Algebras and Algebras of Operators on Banach Spaces, Marcel Dekker, New York, 1974.

3. R. DeVos, Category of sequences of 0's and 1's in some $F K$ spaces, to appear in the Glasgow Math. J.

4. C. Goffman and G. N. Wollan, Sequences of regular summability matrices, Monats. für Math., 76 (1972), 118-120.

5. I. J. Maddox, Elements of Functional Analysis, Cambridge Univ. Press, 1970.

6. G. M. Petersen, Summability fields which span the bounded sequences densely, Bull. London Math. Soc., 5 (1973), 187-191.

7. — Addendum: Summability fields which span the bounded sequences densely, Bull. London Math. Soc., 7 (1975), 105.

8. A. Wilansky, Functional Analysis, Blaisdell, New York, 1964.

Received April 4, 1977 and in revised form August 8, 1977.

VILLANOVA UNIVERSITY

VILLANOVA, PA 19085 


\section{PACIFIC JOURNAL OF MATHEMATICS}

\section{EDITORS}

RICHARD ARENS (Managing Editor)

University of California

Los Angeles, CA 90024

Charles W. Curtis

University of Oregon

Eugene, OR 97403

C. C. Moore

University of California

Berkeley, CA 94720

\section{J. DugundJI}

Department of Mathematics

University of Southern California

Los Angeles, CA 90007

R. FInN and J. Milgram

Stanford University

Stanford, CA 94305

\section{ASSOCIATE EDITORS}
E. F. BECKENBACH
B. H. NeumanN
F. WOLF
K. YoSHIDA

\section{SUPPORTING INSTITUTIONS}

\author{
UNIVERSITY OF BRITISH COLUMBIA \\ CALIFORNIA INSTITUTE OF TECHNOLOGY \\ UNIVERSITY OF CALIFORNIA \\ MONTANA STATE UNIVERSITY \\ UNIVERSITY OF NEVADA, RENO \\ NEW MEXICO STATE UNIVERSITY \\ OREGON STATE UNIVERSITY \\ UNIVERSITY OF OREGON
}

\author{
UNIVERSITY OF SOUTHERN CALIFORNIA \\ STANFORD UNIVERSITY \\ UNIVERSITY OF HAWAII \\ UNIVERSITY OF TOKYO \\ UNIVERSITY OF UTAH \\ WASHINGTON STATE UNIVERSITY \\ UNIVERSITY OF WASHINGTON
}

The Supporting Institutions listed above contribute to the cost of publication of this Journal, but they are not owners or publishers and have no responsibility for its content or policies.

Mathematical papers intended for publication in the Pacific Journal of Mathematics should be in typed form or offset-reproduced, (not dittoed), double spaced with large margins. Please do not use built up fractions in the text of the manuscript. However, you may use them in the displayed equations. Underline Greek letters in red, German in green, and script in blue. The first paragraph or two must be capable of being used separately as a synopsis of the entire paper. Items of the bibliography should not be cited there unless absolutely necessary, in which case they must be identified by author and journal, rather than by item number. Manuscripts, in triplicate, may be sent to any one of the editors. Please classify according to the scheme of Math. Reviews, Index to Vol. 39. All other communications should be addressed to the managing editor, or Elaine Barth, University of California, Los Angeles, California, 90024.

50 reprints to each author are provided free for each article, only if page charges have been substantially paid. Additional copies may be obtained at cost in multiples of 50 .

The Pacific Journal of Mathematics is issued monthly as of January 1966. Regular subscription rate: $\$ 72.00$ a year (6 Vols., 12 issues). Special rate: $\$ 36.00$ a year to individual members of supporting institutions.

Subscriptions, orders for numbers issued in the last three calendar years, and changes of address should be sent to Pacific Journal of Mathematics, 103 Highland Boulevard, Berkeley, California, 94708. Older back numbers obtainable from Kraus Periodicals Co., Route 100, Millwood, NY 10546.

PUBLISHED BY PACIFIC JOURNAL OF MATHEMATICS, A NON-PROFIT CORPORATION

Printed at Kokusai Bunken Insatsusha (International Academic Printing Co., Ltd.). 8-8, 3-chome, Takadanobaba, Shinjuku-ku, Tokyo 160, Japan.

Copyright (C) 1978 by Pacific Journal of Mathematics

Manufactured and first issued in Japan 


\section{Pacific Journal of Mathematics

Vol. 74, No. $2 \quad$ June, 1978

Aharon Atzmon, Spectral synthesis in some spaces of bounded continuous

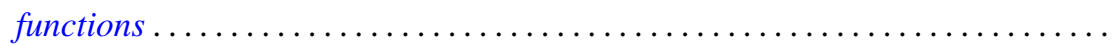

Karl Egil Aubert and Isidor Fleischer, Tensor products of ideal systems and their modules.............................................

Richard F. Basener, Several dimensional properties of the spectrum of a uniform

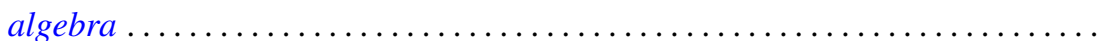

R. H. Bing and Michael Peter Starbird, Super triangulations ............. 307

Andrew Carson, Coherent polynomial rings over regular rings of finite index .....

Robert M. DeVos and Frederick W. Hartmann, Sequences of bounded summability domains .................................................

George Grätzer and R. Padmanabhan, Symmetric difference in abelian groups ....

Robert L. Griess, Jr., A remark about groups of characteristic 2-type and

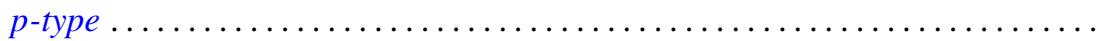

Emil Grosswald and F. J. Schnitzer, A class of modified $\zeta$ and L-functions........

Jutta Hausen and Johnny Albert Johnson, Ideals and radicals of some

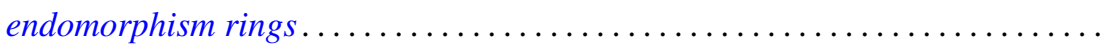

Jean Ann Larson, A solution for scattered order types of a problem of Hagendorf ............................................

Peter A. McCoy, Extremal properties of real biaxially symmetric potentials in $E^{2(\alpha+\beta+2)}$

Héctor Alfredo Merklen, Hereditary crossed product orders .

Hal G. Moore and Adil Mohamed Yaqub, Equational definability of addition in certain rings...

Robert Laurens Moore, Reductivity in $C^{*}$-algebras and essentially reductive operators. . .

Joseph Alvin Neisendorfer, Lie algebras, coalgebras and rational homotopy theory for nilpotent spaces...

William Raymond Nico, Bounded monoids

Richard Paul Osborne, Simplifying spines of 3-manifolds ...

Richard Paul Osborne, The simplest closed 3-manifolds. With an appendix by Osborne and J. Yelle.

Clayton Collier Sherman, The $K$-theory of an equicharacteristic discrete valuation ring injects into the $K$-theory of its field of quotients.... .

Mitchell Herbert Taibleson, The failure of even conjugate characterizations of $H^{1}$

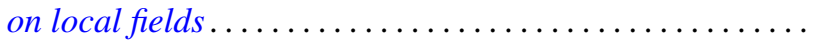

Keti Tenenblat, On characteristic hypersurfaces of submanifolds in Euclidean space ...................................

Jeffrey L. Tollefson, Involutions of Seifert fiber spaces..........

Joel Larry Weiner, An inequality involving the length, curvature, and torsions of a curve in Euclidean $n$-space .......................

Neyamat Zaheer, On generalized polars of the product of abstract homogeneous polynomials.... 